Article

\title{
Anti-Cancer Drug Sensitivity Assay with Quantitative Heterogeneity Testing Using Single-Cell Raman Spectroscopy
}

\author{
Yong Zhang ${ }^{1,2} \mathbb{D}$, Jingjing $\mathrm{Xu}^{3}$, Yuezhou $\mathrm{Yu}^{3}$, Wenhao Shang ${ }^{3}$ and Anpei Ye ${ }^{1,3, *}$ \\ 1 Key Laboratory for the Physics and Chemistry of Nanodevices, School of Electronics Engineering and \\ Computer Science, Peking University, No.5 Yiheyuan Road, Beijing 100871, China; \\ zhangyong2006@pku.edu.cn \\ 2 Beijing Institute of Biomedicine, No.15 Xinjiangongmen Road, Beijing 100091, China \\ 3 Academy for Advanced Interdisciplinary Studies, Peking University, No.5 Yiheyuan Road, Beijing 100871, \\ China; xu_jingjing@pku.edu.cn (J.X.); 13811636947@163.com (Y.Y.); wenhao_shang@pku.edu.cn (W.S.) \\ * Correspondence: yap@pku.edu.cn; Tel.: +86-10-6276-2323
}

Received: 27 September 2018; Accepted: 5 November 2018; Published: 7 November 2018

check for updates

\begin{abstract}
A novel anti-cancer drug sensitivity testing (DST) approach was developed based on in vitro single-cell Raman spectrum intensity (RSI). Generally, the intensity of Raman spectra (RS) for a single living cell treated with drugs positively relates to the sensitivity of the cells to the drugs. In this study, five cancer cell lines (BGC 823, SGC 7901, MGC 803, AGS, and NCI-N87) were exposed to three cytotoxic compounds or to combinations of these compounds, and then they were evaluated for their responses with RSI. The results of RSI were consistent with conventional DST methods. The parametric correlation coefficient for the RSI and Methylthiazolyl tetrazolium assay (MTT) was $0.8558 \pm 0.0850$, and the coefficient of determination was calculated as $\mathrm{R}^{2}=0.9529 \pm 0.0355$ for fitting the dose-response curve. Moreover, RSI data for NCI-N87 cells treated by trastuzumab, everolimus (cytostatic), and these drugs in combination demonstrated that the RSI method was suitable for testing the sensitivity of cytostatic drugs. Furthermore, a heterogeneity coefficient $H$ was introduced for quantitative characterization of the heterogeneity of cancer cells treated by drugs. The largest possible variance between RSs of cancer cells were quantitatively obtained using eigenvalues of principal component analysis (PCA). The ratio of $H$ between resistant cells and sensitive cells was greater than 1.5 , which suggested the $H$-value was effective to describe the heterogeneity of cancer cells. Briefly, the RSI method might be a powerful tool for simple and rapid detection of the sensitivity of tumor cells to anti-cancer drugs and the heterogeneity of their responses to these drugs.
\end{abstract}

Keywords: raman spectroscopy; medical optics; biotechnology; drug sensitivity testing; cancer cells

\section{Introduction}

Anti-tumor drug sensitivity testing (DST) is essential for cancer treatment, especially for individualized cancer therapy (ICT) [1-3]. Cancer cells from the same patients or from the same populations of cancer cell lines have significant differences, and this functional and phenotypic heterogeneity is virtually universal. In addition, patients respond uniquely despite the similarity of their cancer histological phenotypes. Drug responses in different treatment phases may vary for the same patient [4-7]. These variations may result in therapeutic failure or toxicity and patient death. Thus, cancer is difficult to cure due to this heterogeneity. ICT is a method directed against cancer heterogeneity, and DST provides an experimental basis of evaluating sensitivity or resistance to ICT in advance $[1,8]$. 
DST can be performed in vivo or in vitro by comparing the therapeutic efficacies of candidate drugs against surgically removed tumor to identify optimal drug selection. For in vivo DST, tumors are xenografted into immune-deficient mice, and drug treatments are applied and evaluated $[9,10]$. DST in vivo is labor intensive, expensive, and technically demanding, which limits its clinical application. DST in vitro is easier and more accessible. There are various sorts of drug sensitivity testing methods in vitro [3], and the MTT assay is commonly used to assess cell viability [11-13]. In vitro DST methods have limitations, including interference of normal cells and chemicals. Traditional DST is based on bulk experimentation which reflects the overall state of the cell samples, so intrasample heterogeneity cannot be quantified. Significant quantity changes of cancer cells are highly important in these measurements, so overlooking malignant tumor cells may cause crucial issues in cancer treatment. Also, targeted (cytostatic) anticancer drugs have fewer inhibitory effects on tumor proliferation compared to cytotoxic anticancer drugs, so conventional DST is unsuitable for evaluating targeted anticancer drugs [3]. Currently, sensitivity to targeted drugs is usually evaluated with molecular biological methods, such as gene mutation analysis [14], gene polymorphism analysis, and detection of gene expression [15]. A recent study also showed the potential of RS to monitor targeted anticancer drug resistance [16].

Single-cell Raman spectrum intensity (RSI) measurements for anti-cancer drug sensitivity assays could overcome the limitations mentioned above. Single-cell Raman spectroscopy (SCRS) can provide detailed quantitative information about individual living cells. It may be used to observe different cells and to detect cellular dynamic variation on the single cell level $[17,18]$. Previously, it was proposed that the therapeutic efficacy of conventional therapy, including chemotherapy, radiotherapy, etc., is affected by the number or the functions of cancer stem cells in tumors, because the cancer treatments induce the cancer stem cells to differentiate into drug resistant cells [3,19-21]. Because stem cells and their derivatives may be distinguished from cancer cells using Raman spectroscopy [22-24], combining this with drug sensitivity testing may present advantages over conventional DST. More importantly, the intensity of SCRS is positively correlated with cell survival state after drug treatment [25-28]. In addition, protein denaturation and DNA degradation related to cell death also can be evaluated by the variability of RSI measurements. Previous experiments have shown that all peaks of SCRS were significantly decreased after cells were treated with chemotherapeutic drugs compared to a control group, and the results obtained with the RSI method were consistent with traditional cytotoxicity assays [25]. Chemotherapeutic drugs typically induce oncosis, which will show up as decreased RS intensity due to cell swelling and its resulting lower density. Furthermore, cancer cell proliferation is decreased after molecularly-targeted drug treatment. The intracellular spatial distribution and metabolism of molecularly-targeted drug in different cancer cells can also be studied by using Raman imaging [29]. In our study, HER2 and mTOR were used as targets for estimating molecularly-targeted drug effects. HER2, a member of the human epidermal growth factor receptor family, is aberrantly expressed in certain malignancies, including breast and gastric cancer, primarily due to HER2 genomic amplification. In HER2-positive malignancies, this protein can stimulate downstream RAS-RAF-ERK and PI3K-PTEN-AKT signaling, and plays a key role in cell proliferation [30]. HER2 is the preferred therapeutic target in such cancers. Trastuzumab is an anti-HER2 monoclonal antibody and a standard therapy for HER2-positive cancers [31-33]. The mammalian target of rapamycin (mTOR) pathway is a central sensor for nutrient and energy availability. It regulates the cell cycle, growth, and proliferation through the PI3K-AKT-mTOR signaling pathway. Everolimus (RAD001) is a rapamycin derivative which inhibits the serine/threonine kinase activity of mTOR, and significantly inhibits tumor growth [34].

Furthermore, unlike the traditional DST method, SCRS measures individual cell responses to drugs. This has advantages for quantitative analysis of cellular heterogeneity. Cellular heterogeneity describes the observation that different tumor cells can show distinct morphological and phenotypic profiles, including cellular morphology, gene expression, metabolism, motility, proliferation, and metastatic potential. Using chemometrics, such as principal component analysis (PCA), the 
heterogeneous characteristics of cancer cells can be quantitatively evaluated after anti-cancer drug treatment. Moreover, RS is label-free and non-contacting, and it can identify cellular abnormal alteration in molecular structure and biochemical compositions prior to cellular morphological changes. RS is thus rapid, low-interference, and has minimal sample requirements.

In this study, we used RSI to assay human gastric carcinoma cells' responses to chemotherapeutic drugs, and compared it to MTT to verify its stability and reproducibility in anti-cancer drug sensitivity assays. The parametric correlation coefficient of drug responses derived from MTT and RSI data were calculated with Pearson's correlation coefficient, and a two-tailed Student's $t$-test was used to assess statistical differences. Pharmacologically, the dose-response relationship describes the change in effect on an organism, tissue, or cells caused by differing levels of exposure (doses) to a drug after a certain exposure time [35], and dose-response curves are often fit to a classical Hill equation [36]. Here, we fit the relationship between drug dose and the cell response (RSI). The results indicated that our experimental data meet the dose-response relationship. Furthermore, we show that RSI can be used for sensitivity testing of targeted anti-cancer drugs. In brief, we propose a new method of quantifying heterogeneous characteristics of cancer cells by treating cells with drugs. This method supplements the existing DST method.

\section{Materials and Methods}

\subsection{Confocal Raman Spectroscopy}

We constructed an optical configuration for the back-scattering RS system (Figure S1 in the Supporting Information) as described previously [37,38]. In brief, a single continuous wave laser of $532 \mathrm{~nm}$ (Excelsior-532-200, Spectra-Physics, Santa Clara, CA, USA) with working power of $40 \mathrm{~mW}$ was coupled into an inverted microscope (Axiovert 200, Zeiss, Oberkochen, Germany). A $100 \times / 1.25$ oil objective (N-Achroplan, Zeiss, Oberkochen, Germany) with a working distance of $0.29 \mathrm{~mm}$ was used for RS measurement. Overall, considering the signal-to-noise ratios (SNR) of RS and photodamage to the cell, an optimal laser power of $20 \mathrm{~mW}$ on the cancer cell was used. The back-scattering Raman light was collected with the same objective and was directed into a spectrometer (SpectraPro2300i, $1200 \mathrm{~g} / \mathrm{mm}$ blazed at $500 \mathrm{~nm}$, Acton Research Co., Acton, MA, USA). A pinhole of $100 \mu$ m diameter was used to create a confocal system. A notch filter (532 nm, Thorlabs, Newton, NJ, USA) was placed before the entrance of the spectrometer to filter Rayleigh scattered light from the sample. Each RS was recorded with a high sensitivity liquid nitrogen-cooled spectroscopic CCD (Spec-10:400BR/LN, Princeton Instruments, Trenton, NJ, USA).

\subsection{Cell Culture}

Five human gastric carcinoma cell lines (BGC 823, SGC 7901, MGC 803, AGS, and NCI-N87) from Beijing Cancer Hospital were used. Prior to experiments, each cell line was placed in standard culture medium: RPMI-1640 medium (Macgene, Hangzhou, China) supplemented with 10\% fetal bovine serum (Tianhang Biological Technology Co. Ltd., Beijing, China) without antibiotics and cultured at $37^{\circ} \mathrm{C}$ with a relative humidity of $95 \%$ and $5 \% \mathrm{CO}_{2}$. Cell lines were expanded (less than five passages) for RS measurements and cryopreserved to conserve the seed stocks.

\subsection{Anti-Cancer Drug Treatment of Cancer Cells}

Cancer cells from one passage were cultured, transferred to culture plates in the logarithmic growth phase, and incubated at $37{ }^{\circ} \mathrm{C}$ in $5 \% \mathrm{CO}_{2}$ before $\mathrm{RS}$ measurements. After cells reached $50 \%$ confluence, drugs were added to the cancer cell plates, and then the drugs and cells were fully mixed by slightly swaying the cell plate. Control groups of cells were used with the same volume of culture medium (with RPMI-1640 medium and fetal bovine serum) and incubated together with experimental groups (drug treatment groups). Before RS measurements, 0.25\% trypsin (Macgene, China) was added to remove cells. Then, $2 \mathrm{~mL}$ complete medium was added to terminate the digestion. Then, cells were 
transferred via pipette to PBS and transferred to a $15 \mathrm{~mL}$ centrifuge tube. Both control and drug-treated cells were washed with PBS three times by centrifugation at $1000 \mathrm{rpm}(800 \times g)$. It should be noted that the dead and disrupted cells were removed during the wash, which ensures that all the cells for the RS measurement were alive. Supernatants were discarded after the wash, and post-centrifugation cells were diluted in $5 \mathrm{~mL}$ PBS and mixed well. Finally, $80 \mu \mathrm{L}$ of each group was measured for RS measurement. For targeted drug treatment for a long duration, culture medium with targeted drugs was renewed every $48 \mathrm{~h}$.

The molecularly-targeted anti-cancer drugs, trastuzumab and everolimus, were applied to human gastric cancer cells NCI-N87, which express HER2 and mTOR simultaneously. The drug effects were assayed using the RSI method.

\subsection{RS Measurements}

To collect RS signals with high SNR, a sample chamber was designed. A cleaned quartz coverslip (CFS-1010, UQG Ltd., Milton, Cambridge, UK, thickness $0.1 \mathrm{~mm}$ ) was fixed at the bottom of the sample chamber (top diameter $8 \mathrm{~mm}$; bottom diameter $6 \mathrm{~mm}$, depth $2 \mathrm{~mm}$ ). Another quartz coverslip was placed on top of the chamber during the experiment to prevent evaporation and contamination. Washed and rinsed cell samples diluted in PBS were placed into the sample chamber. To ensure consistent spectra collection for individual cells, the laser was focused on the cell center (nucleus) for every Raman excitation. The integration time of the CCD was $30 \mathrm{~s}$ for each spectral collection. Living cancer cells were randomly selected for RS data collection at room temperature, and each cell was measured once. No less than 30 isolated cells were measured for each group, and the background spectra surrounding the cells were acquired at the same time.

\subsection{CCK-8 (MTT) Assay and Direct Cell Counting}

The cholecystokinin (CCK-8) assay and direct cell counting are common methods to evaluate drug effects. Here, we used these methods to compare with RSI to verify the RSI method. The 50\% concentration of inhibition (IC50) values from published data and our experimental results were used as reference drug doses [39,40]. For cytotoxicity testing, cancer cells were seeded in 96-well plates which had different gradient concentrations of drugs, and were incubated in order to create dose-response curve. Cells used for RS and CCK-8 assay were incubated under the same conditions. After incubation, cytotoxicity was measured with a CCK-8 kit (Sigma Aldrich, St. Louis, MO, USA) [12]. Optical density at $450 \mathrm{~nm}$ (OD450) was recorded with a Synergy HTX multi-mode reader (BioTek, Winooski, VT, USA). Then, direct cell counting was performed in sync with RS data collection using a hemocytometer. The cell counts were determined as the means of 8 cell groups from two gridded chambers of the hemocytometer.

\subsection{In Vitro Growth Inhibition Assays}

The MTT (3-[4,5-dimethylthiazol-2-yl]-2,5 diphenyl tetrazolium bromide) assay was used to measure cell death using a ratio of light absorption between experimental and control groups. Here, we defined the RS intensity ratios between experimental and control groups as a drug response. Meanwhile, we used a four-parameter dose-response (logistic) curve (4PL) to evaluate the RSI method. The model equation is:

$$
y=b+\frac{t-b}{1+10^{(\log I C 50-x) \times h}}
$$

where $x$ is $\log$-dose or concentration $(\log \mathrm{mol} / \mathrm{L})$, and $y$ is the response or decline in RS intensity or OD 450 for MTT. IC50 is the concentration of drug that gives a response halfway between the maximum and minimum responses. $h$ is the Hill or slope factor (dimensionless), and $t$ and $b$ are the plateaus of the maximum and minimum responses (the maximal and minimal inhibition ratio from three independent assays), respectively. 


\subsection{Quantitative Measurements of the Heterogeneous Drug Responses}

Principle Component Analysis (PCA) finds variables (components) accounting for as much as possible of the variance in multivariate data using. The largest possible variance between RSs of cancer cells were quantitatively calculated by using PCA. PCA uses eigenvalues and eigenvectors of variance-covariance or correlation matrices. Eigenvalues tell the variance accounting for corresponding eigenvectors (components). Full RS data for cancer cells within $450-1800 \mathrm{~cm}^{-1}$ was inputted as PCA variables for each test group, and PAST software [41] was used. An averaged heterogeneity coefficient $H$ was defined as Equation (2):

$$
H=\frac{\sum_{i=n} P C E_{i}}{n},
$$

where $n$ is the cell number in the measurement group; $P C E_{i}$ is the eigenvalues of principal components. By calculating the $H$ ratio (heterogeneity ratio) between drug-treated and control group cancer cell, we can obtain changes in heterogeneity of cancer cells after drug treatment.

\subsection{Experimental Consistency Control}

It is important to keep experimental condition consistency for drug sensitivity assays with the RSI method. Consistency mainly depends on the focus position on the cells with the laser beam, the laser power, and the stability of the Raman spectral setup. The RS system was standardized by measurement of the intensity and peak shift of the RS using a standard $5 \mu \mathrm{m}$ polystyrene bead before each experiment.

The size of the spot of a Raman exciting laser beam on samples can be theoretically calculated

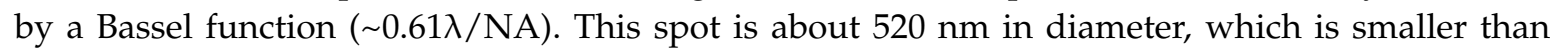
actual laser spot size. The size of the cancer cells in our experiment were $\sim(10-15) \mu \mathrm{m}$, as these cells had large nuclei. For RS measurements, the laser spot was focused on the cellular nucleus to avoid relative "position difference effects". Thus, we created a stable RS curve and blocked organelle interference. Wavelength correction was carried out using a polystyrene bead prior to cell experiments too. For intensity corrections, the laser power before the objective and its relative position on the entrance slit of the spectrometer were held constant in all experiments. RSI fluctuation resulting from the bias of laser focus position on the cells was less than 3\%, which was much less than the change caused by the drug (Figure S2 in Supporting Information). All these above-mentioned measures ensured that the RSI data reflected true cell activity.

\subsection{Data Processing}

RSI data processing was performed using a homemade software based on MATLAB (The MathWorks, Inc., Natick, MA, USA). Spectra were calibrated via the wavelength dependence of a standard $1001 \mathrm{~cm}^{-1}$ vibrational band of polystyrene beads before the RS measurements. For each spectrum, the background noise including the quartz contribution was removed by subtracting the background spectra from the raw spectral data. To do this and remove the effect due to instrument, the raw spectra data need to be normalized. In detail, we applied one inherent Raman peak of $413 \mathrm{~cm}^{-1}$ rooted from immersion oil in all measurements (including background RS) as an interior label, and all raw spectra were normalized by this peak. For every processed RS, the intensity of the main Raman peaks that corresponded to different chemical components related to cell death was extracted for drug response analyses. In addition, the area under the curve (AUC) of RS between $450-1800 \mathrm{~cm}^{-1}$, which represented the ensemble of various components within a cell, was obtained by RS curve integrals.

In this study, we used the changes both of the AUC and the single typical component peaks to evaluate drug effects. The biochemical phenomena related to cell apoptosis or oncosis are very complex. The Nomenclature Committee on Cell Death (NCCD) has proposed that specific biochemical analyses should not be employed as exclusive means to define apoptosis or oncosis, because different types of cell death can occur with different biochemical changes [42]. Moreover, the manner of cell death may obscure biochemical and functional heterogeneity. There may be distinct subtypes of one type 
of cell death which may be morphologically similar but are triggered through different biochemical routes [42-44]. The AUC contained all the changes in the components, which might result in a more accurate and suitable evaluation of the effects of drug treatments.

\section{Results and Discussion}

The chemotherapy-induced cancer cell death that we observed had the typical morphological features of oncosis, including the fact that these cells became bigger than normal living cells, and cellular volume obviously increased with the drug concentration (Figure 1). The averaged Raman spectra for several cancer cells treated with different drugs are shown in Figure 2(a1-e1). The RS peaks correspond to molecular vibrations of cellular components, including nucleic acids, proteins, lipids, and carbohydrates. In eukaryotic cells, the $783 \mathrm{~cm}^{-1}$ band corresponds to the nucleic acid components of RNA or $\alpha \mathrm{DNA}$, namely, the uracil $(\mathrm{U})$, thymine $(\mathrm{T})$, and cytosine $(\mathrm{C})$ ring vibrations. Therefore, major changes related to DNA can be observed at this peak [27,28]. Bands at 1001, 1245, and $1654 \mathrm{~cm}^{-1}$ can be attributed to proteins. The sharp band at $1001 \mathrm{~cm}^{-1}$ corresponds to a symmetric ring-breathing mode of phenylalanine [26,27], which is sensitive to cell death $[25,45,46]$ and can be used for determining whether the cells are dead. The $1245 \mathrm{~cm}^{-1}$ band corresponds to amide III (bonds in $\beta$ sheets), and the 1654 band $\mathrm{cm}^{-1}$ corresponds to amide I ( $\alpha$-helix), which are basic components of protein structure $[18,47]$. The $1446 \mathrm{~cm}^{-1}$ band corresponds to $\mathrm{CH}_{2}$ bending vibrations in proteins, carbohydrates, lipids, and DNA $[25,27,28]$. This demonstrates the single-cell RS intensity changes as a whole.

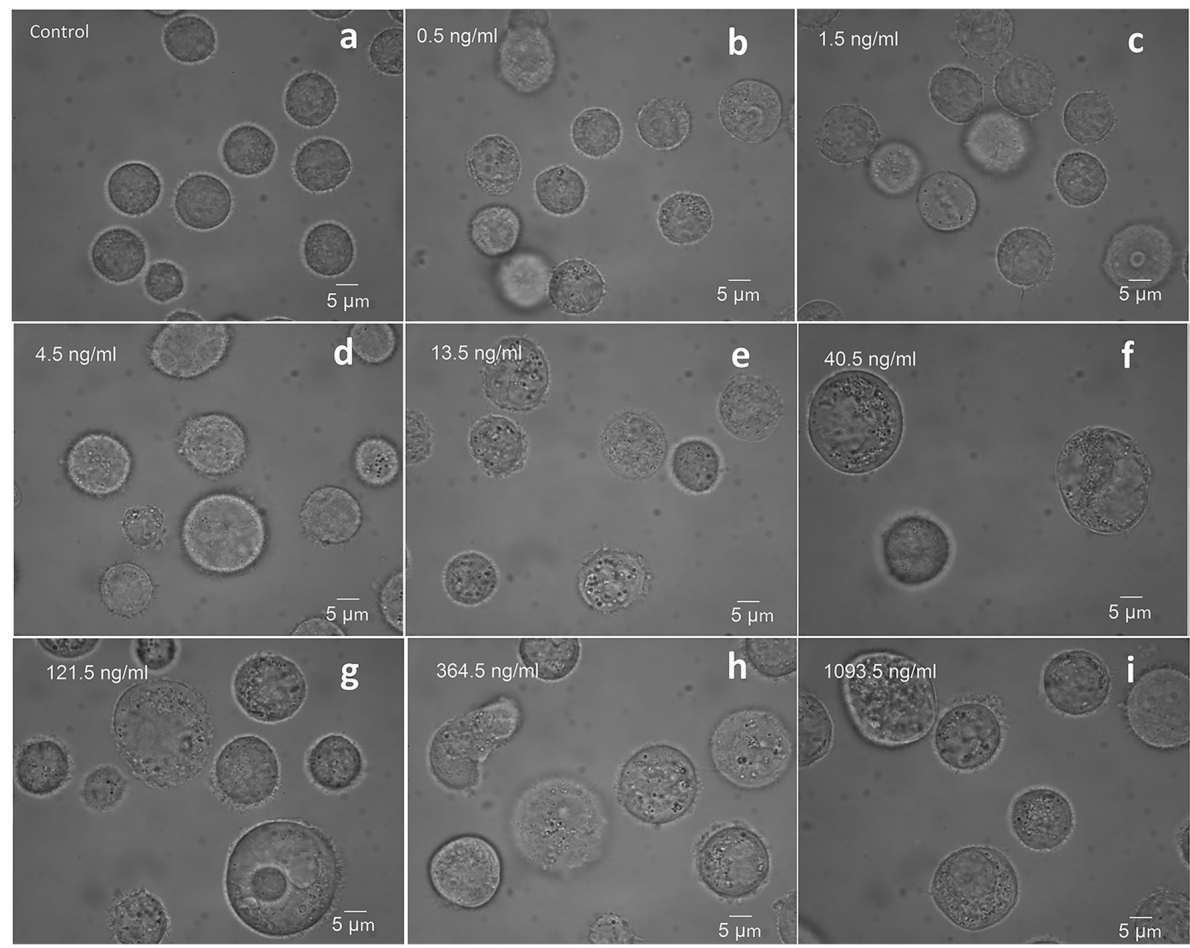

Figure 1. The bright field images of BGC823 cells under conditions of different concentrations of PTX treatment for $48 \mathrm{~h}$. (a) Control group without PTX treatment; (b-i) The morphological change in BGC823 cells with increasing PTX concentrations. The cellular volume obviously increased with the drug concentration.

\subsection{Chemotherapy Drug Dose-Effect Assay}

To evaluate the utility of RSI, we measured drug effects for different cell lines. Figure 2 shows the changes in the mean RS of several cell lines treated with different drugs (Figure 2(a1-e1)) at $24 \mathrm{~h}$, shown the change of their AUCs (Figure 2(a2-e2)), and a typical $1001 \mathrm{~cm}^{-1}$ band (Figure 2(a3-e3)) as 
drug concentration increases. The results showed that the RS peaks of drug-treated cells compared to the peaks form the control group decreased with increasing drug concentration, which suggests that the amount or density of nucleic acid, protein, and lipid could be lower during drug-induced cell death. This spectral presentation was consistent with the fact that the chromatin of the nucleolus and other cellular components is highly fragmented in the oncosis process as the drug concentration increases [25-28]. The quantitative change of the RSI-AUC and the $1001 \mathrm{~cm}^{-1}$ band from drug treated cancer cells express dose-response relationships. To verify the feasibility of RSI we compared RSI with MTT, the results are shown in Table 1 , and the coefficient of determination, $R^{2}$, was calculated from Equation (1). The mean coefficients of determination (computed by the least squares method) for the AUC were greater than that of RS- $1001 \mathrm{~cm}^{-1}$ and lower than the MTT values. All $\mathrm{R}^{2}$ values were high, indicating that the MTT and RSI methods fitted the dose-response curves well.
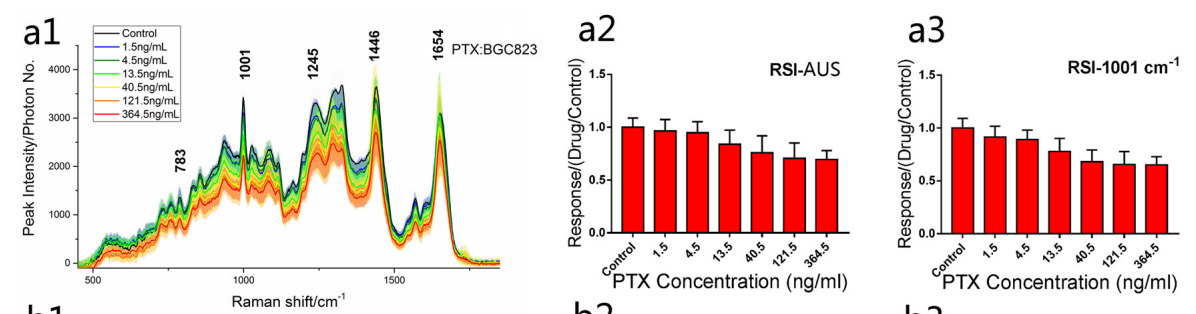

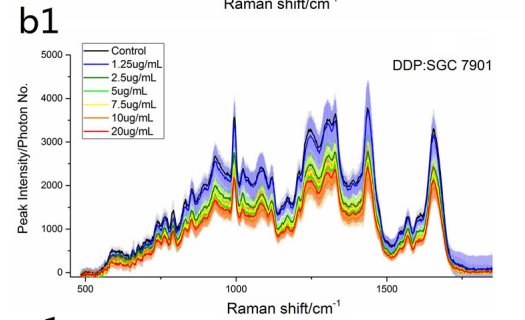

\section{b2}

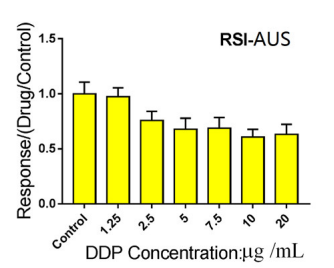

C2

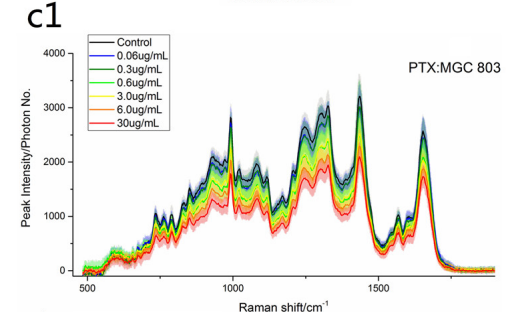

d1

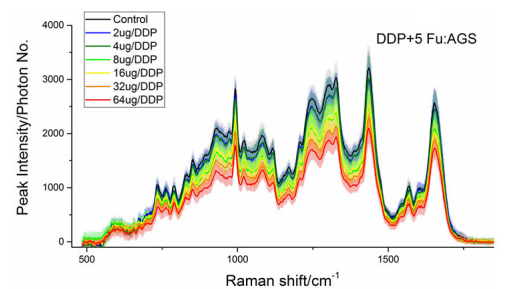

e1

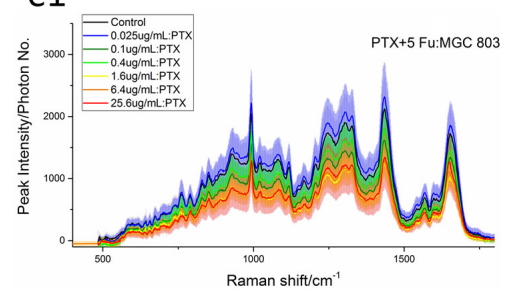

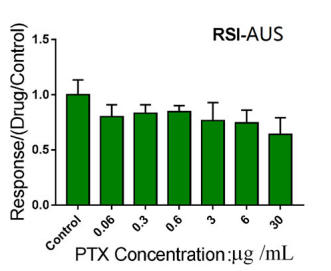

d2

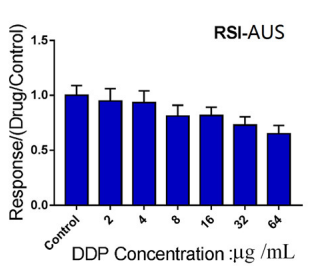

e2

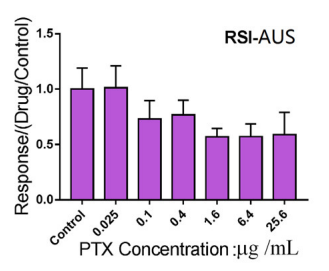

b3

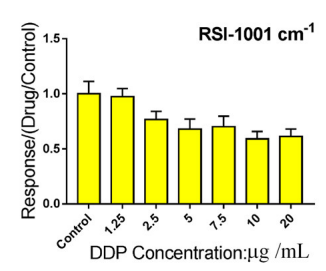

c3

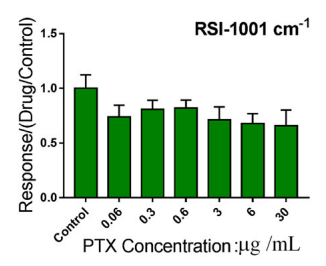

d3

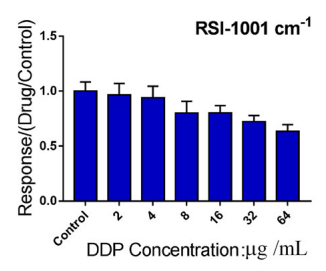

e3

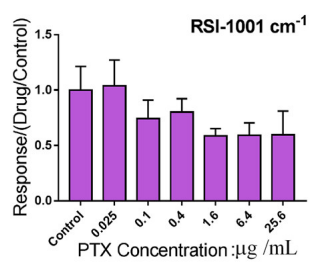

Figure 2. Dose-response relationships for different cancer cell lines with different anti-cancer drug treatments (expressed as drug(s): cell). (a-e), BGC823, SGC7901, MGC803, AGS, or MGC803 cells treated with concentration gradients of the drugs PTX, DDP, PTX, and combinations of DDP and $5 \mathrm{Fu}$, or PTX and $5 \mathrm{Fu}$, respectively; (a1-e1), the averaged RS from different drug concentrations; (a2-e2), the averaged RS area; (a3-e3), the $1001 \mathrm{~cm}^{-1}$ band; the averaged RSs and bar graphs present mean \pm s.d., $\mathrm{n} \geq 30$ cells per condition. $p<0.001$ for all groups (a one-way ANOVA). 
Table 1. Coefficient of determination $\left(\mathrm{R}^{2}\right)$ for RSI and MTT fitting.

\begin{tabular}{cccc}
\hline Test Groups & AUC & RSI-1001 $\mathbf{~ m}^{-\mathbf{1}}$ & CCK-8 (MTT) \\
\hline PTX: BGC 823 & 0.9960 & 0.9995 & 0.9726 \\
DDP: SGC 7901 & 0.9721 & 0.9518 & 0.9961 \\
PTX: MGC 803 & 0.9424 & 0.8528 & 0.9761 \\
DDP + 5-Fu: AGS & 0.9531 & 0.9540 & 0.9949 \\
PTX + 5-Fu: MGC 803 & 0.9009 & 0.9009 & 0.8838 \\
\hline Mean R & $0.9529 \pm 0.0355$ & $0.9315 \pm 0.0565$ & $0.9647 \pm 0.0465$ \\
\hline
\end{tabular}

Furthermore, regression analyses of the correlation coefficients between RSI and MTT, which express the correlation between RSI and MTT, were performed and the data are presented in Table 2 . For the AUC and RSI-1001 cm $\mathrm{cm}^{-1}$, the correlation coefficients were highly consistent for all kind of cells and drugs, and for the AUC and MTT it was also consistent. The results indicate that both the AUC of RS and RAI-1001 can be used to evaluate drug sensitivity like MTT can. Meanwhile, we noticed that there are a few smaller correlation coefficients between the MTT and RSI methods, such as the case of the MGC803 cells treated with PTX, with a comparison between RSI- $1001 \mathrm{~cm}^{-1}$ and MTT. This suggests that RSI is not exactly same as MTT in drug sensitivity assays because they have different evaluation criteria. Moreover, we observed that the difference between the RSI and MTT increased with drug dose. MTT was more sensitive at higher doses, due to the fact that the number of living cells decreased rapidly as drug concentration increased, while RSI evaluated the survival state of living cells.

Table 2. Regression analyses for correlation coefficients between the RSI and MTT methods.

\begin{tabular}{cccc}
\hline Test Groups & AUC: MTT & RSI-1001 $\mathbf{~ m}^{-\mathbf{1}}: \mathbf{M T T}$ & AUC:RSI-1001 $\mathbf{~ m}^{-\mathbf{1}}$ \\
\hline PTX: BGC823 & $0.9267\left(p^{1}=0.008\right)$ & $0.9051(p=0.013)$ & $0.9956(p<0.000)$ \\
DDP: SGC7901 & $0.7352(p=0.096)$ & $0.7713(p=0.072)$ & $0.9961(p<0.000)$ \\
PTX: MGC803 & $0.9316(p=0.007)$ & $0.6963(p=0.124)$ & $0.9021(p=0.014)$ \\
DDP + 5Fu: AGS & $0.8832(p=0.019)$ & $0.8705(p=0.024)$ & $0.9986(p<0.000)$ \\
PTX + 5Fu: MGC803 & $0.8024(p=0.054)$ & $0.8171(p=0.047)$ & $0.9992(p<0.000)$ \\
\hline \multicolumn{4}{c}{${ }^{1} p$ value: the two-tailed probabilities that two testing results were uncorrelated. }
\end{tabular}

\subsection{Quantification of Heterogeneous Drug Responses}

We used the $H$ ratio between drug-treated and control cells to describe the heterogeneous drug responses quantitatively. Figure 3 shows the RSI changes with cell drug exposure time for BGC823 cells treated with PTX and AGS cells treated with 5-FU. RS was collected every $6 \mathrm{~h}$ for $48 \mathrm{~h}$. The results showed that cancer cells exposed to high concentrations of drugs for a long time became resistant. The numbers of living cells declined over $48 \mathrm{~h}$ due to drug-induced cell death (Figure S3 in Supporting Information). However, the RSI first decreased and then increased over the drug treatment time. For BGC823 cells, the RSI diminished initially and then increased after $24 \mathrm{~h}$ compared to controls. For AGS cells, likewise, the RSI became the lowest at $30 \mathrm{~h}$. We think that the decrease in RSI resulted from drug-induced cell oncosis. Subsequent RSI increases were likely due to drug resistance of cells, because drug-sensitive cells were dead and were removed in the cell washing and centrifugation process. This was probably due to poor adaptation during long times of drug treatment, only the remaining drug-resistant cells were assayed with RSI. Other researchers have also reported similar results [27]. Since longer drug treatment times correlated to higher proportions of drug-resistant cell, the mean RSI increased with drug treatment time after $24 \mathrm{~h}$. Moreover, the heterogeneity ratio between treated and control cells significantly increased with drug treatment time after $24 \mathrm{~h}$ for BGC823 and $30 \mathrm{~h}$ for AGS (Figure 3c,f), just as RSI increased. It follows that the heterogeneous characteristics of cancer cells became highlighted as drug-resistant characteristics increased. 


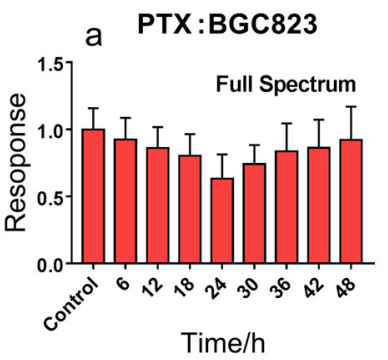

b
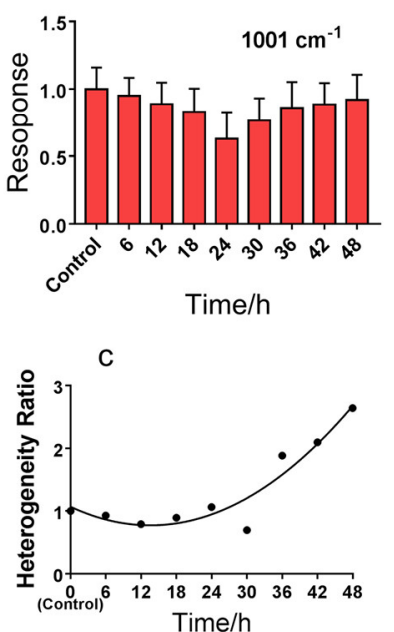

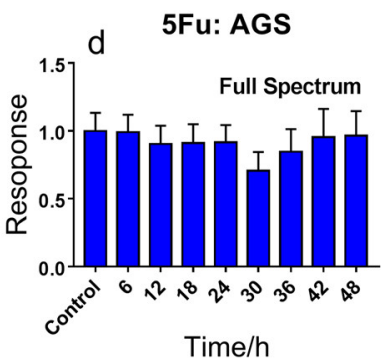

e
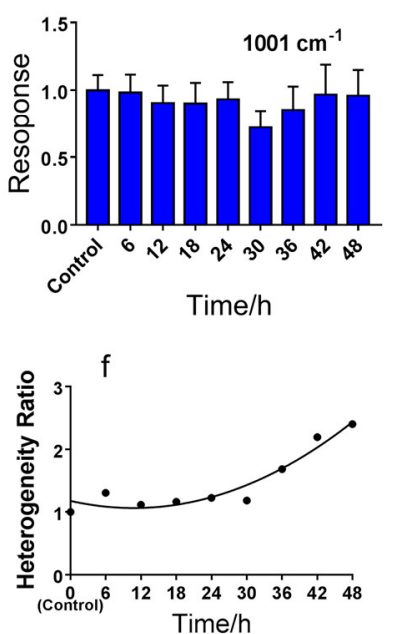

Figure 3. Drug response and heterogeneity changes for different cancer cell lines treated with anti-cancer drugs for multiple culture durations. (a,b), BGC 823 cells treated with $140 \mathrm{ng} / \mathrm{mL}$ PTX ( IC50). (d,e), AGS cells treated with $30 \mu \mathrm{g} / \mathrm{mL}$ PTX $(\sim 2 \times$ IC50). Bars represent the mean \pm s.d. (c,f), the heterogeneity ratio changes with drug treatment time for BGC 823 and AGS cells. The curve is a result of quadratic function fitting. Cell number was $n \geq 30$ in each group. Data were collected every $6 \mathrm{~h}$ for $48 \mathrm{~h}$.

\subsection{Targeted Drug Growth/Inhibitor Evaluations}

In order to evaluate the feasibility of RSI applied in the targeted drug sensitivity assay, trastuzumab and everolimus were applied to NCI-N87 cells. Bright field images showed no significant difference in morphological features between treated and control groups for either of the targeted drugs, but there was a significant difference in RSI. This indicates that cell morphological change measurements are not reliable for evaluating effects of targeted anti-cancer drugs, especially for drug induced non-oncosis cell death. Figure 4 shows the RSI measurement results for NCI-N87 cells treated with trastuzumab or everolimus alone and in combination for 24,48 , and $72 \mathrm{~h}$. The response of the cells treated with trastuzumab was not significantly different at 24 and $72 \mathrm{~h}$, but at $48 \mathrm{~h}$, it had a significant difference between treated and control groups. While for NCI-N87 cells treated with everolimus alone or in combination, the responses of the treated groups were significantly different from controls at all time points $(p<0.0001)$. In addition, in comparison to trastuzumab, everolimus has a significantly inhibitory activity on the proliferation of NCI-N87 cells, although the inhibitory effects were the most obvious for the combination of the two drugs. These results are in agreement with published data $[48,49]$. 

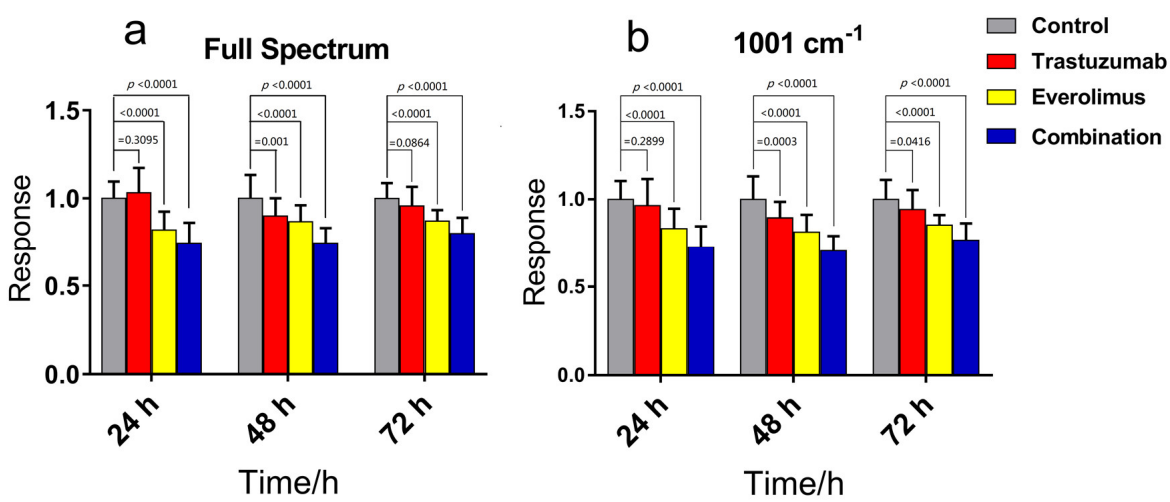

Figure 4. The RSI method to measure molecularly targeted anti-cancer drug effects. Trastuzumab $(250 \mathrm{nM})$ and everolimus (20 $\mathrm{nM}$, referring to the plasma concentration) were used singly or together. Bars represent mean \pm s.d. of drug treated cells to control cells, $\mathrm{n} \geq 30$ cells per group. Data were collected at 24, 48, and 72 h. $p$ value: two-tailed Student's $t$-test.

The long-term inhibitory effect of everolimus and heterogeneous characteristics of NCI-N87 were studied using RSI. NCI-N87 cells were treated with $20 \mathrm{nM}$ everolimus, and data were collected every $24 \mathrm{~h}$ for 7 days (See Figure 5). In spite of the fact that the cell number grew with time, the proliferation rates of NCI-N87 cells in the everolimus group was clearly lower than in the control group (Figure 5a), which indicated that the targeted drug had significant inhibitory effects. However, this indicated that unlike chemotherapeutics, the targeted drug did not induce cancer cell death but inhibited cancer cell proliferation. Moreover, RSI also showed that everolimus significantly inhibited the growth of NCI-N87 cells compared to controls (Figure 5c,d). Compare to the cytotoxic drug treatment (Figure 3c,f), the heterogeneous ratio fluctuations were not obvious over the 7 days (Figure 5b), illustrating that molecularly targeted drugs have less possibility to induce drug resistance.
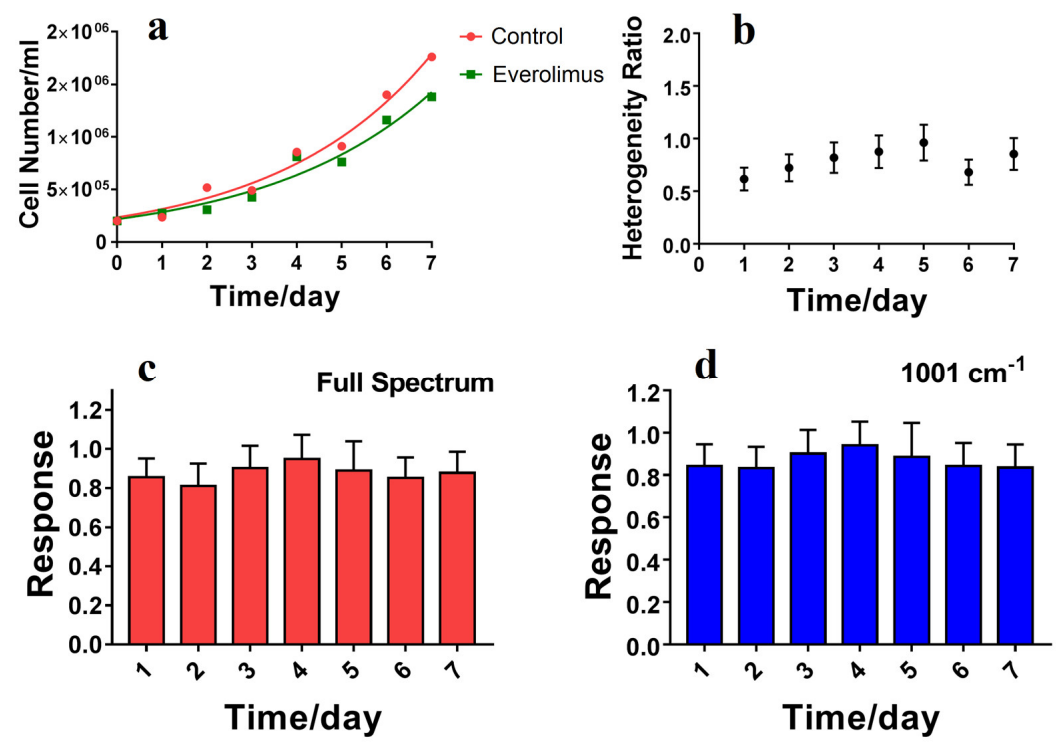

Figure 5. The long-term inhibitory effect and changes in heterogeneous characteristics due to everolimus treatment of NCI-N87. (a) Exponential fittings of proliferation rates of NCI-N87 cells. The rate constant for the control group was 0.2904 and the doubling-time was 2.387 days, with $\mathrm{R}^{2}=0.9785$. The rate constant for the everolimus group was 0.2684 , with a doubling-time of 2.853 days and $\mathrm{R}^{2}=0.9622$; (b) Changes in the heterogeneous characteristics of NCI-N87 cells with the everolimus treatment time. The s.d. of the heterogeneity obtained from control groups over 7 days; (c) The drug response of NCI-N87 cells with everolimus treatment (RSI-AUC); (d) The drug response of NCI-N87 cells with everolimus treatment (RSI-1001 $\mathrm{cm}^{-1}$ ). Bars represent the mean \pm s.d. of drug treated cells to control cells, $\mathrm{n} \geq 30$. 


\section{Conclusions}

We proposed a drug sensitivity testing method using RSI which is consistent with conventional DST methods, such as MTT and direct cell counting. The RSI method can overcome the limitations of conventional DST methods, such as being unsuitable for targeted drugs. RSI can provide a new method for quantifying the heterogeneity of cancer cell responses to anti-cancer drugs. RSI gives a possible approach for molecularly targeted anti-cancer drug sensitivity testing by measuring cell viability. This research shows that label-free RSI is a sensitive and multi-functional method for anti-cancer drug sensitivity.

Supplementary Materials: Supplementary materials are available online: Figure S1: Configuration of the Raman spectroscopy. A single laser beam at the wavelength of $532 \mathrm{~nm}$ is directed to the microscope via dichroic mirrors (D1) and coupled into the objective with free working distance of $0.29 \mathrm{~mm}$. The back scattering Raman light is collected by the same objective and then delivered into the spectrometer via a dichroic mirror (D2). A pinhole with a diameter of $100 \mu \mathrm{m}$ was used to create a confocal system. A notch filter is placed before the entrance of the spectrometer to filter the Rayleigh scattered light from the sample. The RS is finally recorded with a liquid nitrogen (LN)-cooled spectroscopic CCD, Figure S2: The focusing position controls under a bright light view of the cell. The axial position can be controlled with $\sim 1 \mu \mathrm{m}$ precision by observing the edge of the cell under a bright light view. When focusing on the center of the cell accurately, a bright and fine ring is seen on the edge of the cell due to the bright light. The ring would become dark and wide when out of focus. (a-e), The axial focusing position from $2 \mu \mathrm{m}$ above the cell center to $2 \mu \mathrm{m}$ below the cell center. (f) The RS corresponding to (a-e). The differences in the area under the curves and between lines at $0 \mu \mathrm{m}$ and $\pm 1 \mu \mathrm{m}$ were less than $2.8 \%$. This is less than the change caused by the drug, Figure S3: Cell counts of cancer cells over drug treatment every $6 \mathrm{~h}$ for 48 h. (a) BGC 823 cells under $140 \mathrm{ng} / \mathrm{mL}$ PTX treatment. (b) AGS cells under $30 \mathrm{\mu g} / \mathrm{mL}$ PTX treatment.

Author Contributions: Conceptualization, Y.Z. and A.Y.; methodology, Y.Z.; formal analysis, Y.Z., J.X., Y.Y. and W.S.; investigation, Y.Z., J.X., Y.Y. and W.S.; resources, Y.Y. and W.S.; data curation, Y.Z.; writing-original draft preparation, Y.Z.; writing-review and editing, A.Y.

Funding: This research was funded by the National Natural Science Foundation of China (NSFC), grant number U1636110.

Acknowledgments: The authors thank Lin Shen, Jing Gao, and Yilin Li of Peking University Cancer Hospital and Institute for technical support, and providing the cancer cells.

Conflicts of Interest: The authors declare no conflict of interest.

\section{References}

1. Samson, D.J.; Seidenfeld, J.; Ziegler, K.; Aronson, N. Chemotherapy sensitivity and resistance assays: A systematic review. J. Clin. Oncol. 2004, 22, 3618-3630. [CrossRef] [PubMed]

2. Ulukaya, E. Drug response assay: An increasing trend in designation of tailored-chemotherapy for more rational management of cancer patients. Adv. Mol. Med. 2006, 2, 53-58.

3. Lu, D.-Y.; Lu, T.-R.; Ding, J.; Xu, B.; Che, J.-Y.; Wu, H.-Y. Anticancer drug sensitivity testing, a historical review and future perspectives. Curr. Drug Ther. 2015, 10, 11. [CrossRef]

4. Bedard, P.L.; Hansen, A.R.; Ratain, M.J.; Siu, L.L. Tumour heterogeneity in the clinic. Nature 2013, 501, 355-364. [CrossRef] [PubMed]

5. Meacham, C.E.; Morrison, S.J. Tumour heterogeneity and cancer cell plasticity. Nature 2013, 501, 328-337. [CrossRef] [PubMed]

6. Junttila, M.R.; de Sauvage, F.J. Influence of tumour micro-environment heterogeneity on therapeutic response. Nature 2013, 501, 346-354. [CrossRef] [PubMed]

7. Burrell, R.A.; McGranahan, N.; Bartek, J.; Swanton, C. The causes and consequences of genetic heterogeneity in cancer evolution. Nature 2013, 501, 338-345. [CrossRef] [PubMed]

8. Kubota, T.; Egawa, T.; Otani, Y.; Furukawa, T.; Saikawa, Y.; Yoshida, M.; Watanabe, M.; Kumai, K.; Kitajima, M. Cancer chemotherapy chemosensitivity testing is useful in evaluating the appropriate adjuvant cancer chemotherapy for stages iii/iv gastric cancers without peritoneal dissemination. Anticancer Res. 2003, 23, 583-587. [PubMed]

9. Lu, D.Y. Similarity of drug sensitivity test results on human pulmonary adenocarcinoma xenografts transplanted under the subrenal capsules between normal immunocompetent and immunodeficient athymic mice. Int. J. Pharm. Ther. 2010, 1, 106-109. 
10. Aamdal, S.; Fodstad, O.; Nesland, J.M.; Pihl, A. Characteristics of human tumour xenografts transplanted under the renal capsule of immunocompetent mice. Br. J. Cancer 1985, 51, 347-356. [CrossRef] [PubMed]

11. Alley, M.C.; Scudiero, D.A.; Monks, A.; Hursey, M.L.; Czerwinski, M.J.; Fine, D.L.; Abbott, B.J.; Mayo, J.G.; Shoemaker, R.H.; Boyd, M.R. Feasibility of drug screening with panels of human tumor cell lines using a microculture tetrazolium assay. Cancer Res. 1988, 48, 589-601. [PubMed]

12. Tominaga, H.; Ishiyama, M.; Ohseto, F.; Sasamoto, K.; Hamamoto, T.; Suzuki, K.; Watanabe, M. A water-soluble tetrazolium salt useful for colorimetric cell viability assay. Anal. Commun. 1999, 36, 47-50. [CrossRef]

13. Xiao, Y.; Li, J.-D.; Shi, H.-L.; Liu, J.-H.; Feng, Y.-L.; Li, M.-D. Predictive value of in vitro mtt assay chemosensitivity test of cytotoxic drug activity in cervical cancer. Ai Zheng 2007, 26, 386-389. [PubMed]

14. Debiec-Rychter, M.; Dumez, H.; Judson, I.; Wasag, B.; Verweij, J.; Brown, M.; Dimitrijevic, S.; Sciot, R.; Stul, M.; Vranck, H.; et al. Use of c-kit/pdgfra mutational analysis to predict the clinical response to imatinib in patients with advanced gastrointestinal stromal tumours entered on phase $i$ and ii studies of the eortc soft tissue and bone sarcoma group. Eur. J. Cancer 2004, 40, 689-695. [CrossRef] [PubMed]

15. Demonty, G.; Bernard-Marty, C.; Puglisi, F.; Mancini, I.; Piccart, M. Progress and new standards of care in the management of her-2 positive breast cancer. Eur. J. Cancer 2007, 43, 497-509. [CrossRef] [PubMed]

16. Hammoud, M.K.; Yosef, H.K.; Lechtonen, T.; Aljakouch, K.; Schuler, M.; Alsaidi, W.; Daho, I.; Maghnouj, A.; Hahn, S.; El-Mashtoly, S.F.; et al. Raman micro-spectroscopy monitors acquired resistance to targeted cancer therapy at the cellular level. Sci. Rep. 2018, 8, 15278. [CrossRef] [PubMed]

17. Austin, L.A.; Osseiran, S.; Evans, C.L. Raman technologies in cancer diagnostics. Analyst 2016, 141, $476-503$. [CrossRef] [PubMed]

18. Schie, I.W.; Huser, T. Methods and applications of raman microspectroscopy to single-cell analysis. Appl. Spectrosc. 2013, 67, 813-828. [CrossRef] [PubMed]

19. Visvader, J.E.; Lindeman, G.J. Cancer stem cells in solid tumours: Accumulating evidence and unresolved questions. Nat. Rev. Cancer 2008, 8, 755-768. [CrossRef] [PubMed]

20. Li, Y.; Laterra, J. Cancer stem cells: Distinct entities or dynamically regulated phenotypes? Cancer Res. 2012, 72, 576-580. [CrossRef] [PubMed]

21. Magee, J.A.; Piskounova, E.; Morrison, S.J. Cancer stem cells: Impact, heterogeneity, and uncertainty. Cancer Cell 2012, 21, 283-296. [CrossRef] [PubMed]

22. Chan, J.W.; Lieu, D.K.; Huser, T.; Li, R.A. Label-free separation of human embryonic stem cells and their cardiac derivatives using raman spectroscopy. Anal. Chem. 2009, 81, 1324-1331. [CrossRef] [PubMed]

23. Harkness, L.; Novikov, S.M.; Beermann, J.; Bozhevolnyi, S.I.; Kassem, M. Identification of abnormal stem cells using raman spectroscopy. Stem Cells Dev. 2012, 21, 2152-2159. [CrossRef] [PubMed]

24. Manikandan, M.; Nasser Abdelhamid, H.; Talib, A.; Wu, H.F. Facile synthesis of gold nanohexagons on graphene templates in raman spectroscopy for biosensing cancer and cancer stem cells. Biosens. Bioelectron. 2014, 55, 180-186. [CrossRef] [PubMed]

25. Jung, G.B.; Lee, Y.J.; Lee, G.; Park, H.K. A simple and rapid detection of tissue adhesive-induced biochemical changes in cells and DNA using raman spectroscopy. Biomed. Opt. Express 2013, 4, 2673-2682. [CrossRef] [PubMed]

26. Yao, H.; Tao, Z.; Ai, M.; Peng, L.; Wang, G.; He, B.; Li, Y.-Q. Raman spectroscopic analysis of apoptosis of single human gastric cancer cells. Vib. Spectrosc. 2009, 50, 193-197. [CrossRef]

27. Buckmaster, R.; Asphahani, F.; Thein, M.; Xu, J.; Zhang, M. Detection of drug-induced cellular changes using confocal raman spectroscopy on patterned single-cell biosensors. Analyst 2009, 134, 1440-1446. [CrossRef] [PubMed]

28. Huang, H.; Shi, H.; Feng, S.; Chen, W.; Yu, Y.; Lin, D.; Chen, R. Confocal raman spectroscopic analysis of the cytotoxic response to cisplatin in nasopharyngeal carcinoma cells. Anal. Methods 2013, 5, 260-266. [CrossRef]

29. Aljakouch, K.; Lechtonen, T.; Yosef, H.K.; Hammoud, M.K.; Alsaidi, W.; Kotting, C.; Mugge, C.; Kourist, R.; El-Mashtoly, S.F.; Gerwert, K. Raman microspectroscopic evidence for the metabolism of a tyrosine kinase inhibitor, neratinib, in cancer cells. Angew. Chem. Int. Ed. 2018, 57, 7250-7254. [CrossRef] [PubMed]

30. Yan, M.; Parker, B.A.; Schwab, R.; Kurzrock, R. Her2 aberrations in cancer: Implications for therapy. Cancer Treat. Rev. 2014, 40, 770-780. [CrossRef] [PubMed] 
31. Takegawa, N.; Nonagase, Y.; Yonesaka, K.; Sakai, K.; Maenishi, O.; Ogitani, Y.; Tamura, T.; Nishio, K.; Nakagawa, K.; Tsurutani, J. Ds-8201a, a new her2-targeting antibody-drug conjugate incorporating a novel DNA topoisomerase i inhibitor, overcomes her2-positive gastric cancer t-dm1 resistance. Int. J. Cancer 2017, 141, 1682-1689. [CrossRef] [PubMed]

32. Bang, Y.-J.; Van Cutsem, E.; Feyereislova, A.; Chung, H.C.; Shen, L.; Sawaki, A.; Lordick, F.; Ohtsu, A.; Omuro, Y.; Satoh, T.; et al. Trastuzumab in combination with chemotherapy versus chemotherapy alone for treatment of her2-positive advanced gastric or gastro-oesophageal junction cancer (toga): A phase 3, open-label, randomised controlled trial. Lancet 2010, 376, 687-697. [CrossRef]

33. Fujimoto-Ouchi, K.; Sekiguchi, F.; Yasuno, H.; Moriya, Y.; Mori, K.; Tanaka, Y. Antitumor activity of trastuzumab in combination with chemotherapy in human gastric cancer xenograft models. Cancer Chemother. Pharm. 2007, 59, 795-805. [CrossRef] [PubMed]

34. Cejka, D.; Preusser, M.; Woehrer, A.; Sieghart, W.; Strommer, S.; Werzowa, J.; Fuereder, T.; Wacheck, V. Everolimus (rad001) and anti-angiogenic cyclophosphamide show long-term control of gastric cancer growth in vivo. Cancer Biol. Ther. 2014, 7, 1377-1385. [CrossRef]

35. Crump, K.S.; Hoel, D.G.; Langley, C.H.; Peto, R. Fundamental carcinogenic processes and their implications for low dose risk assessment. Cancer Res. 1976, 36, 2973-2979. [PubMed]

36. Di Veroli, G.Y.; Fornari, C.; Goldlust, I.; Mills, G.; Koh, S.B.; Bramhall, J.L.; Richards, F.M.; Jodrell, D.I. An automated fitting procedure and software for dose-response curves with multiphasic features. Sci. Rep. 2015, 5, 14701. [CrossRef] [PubMed]

37. Ma, H.; Zhang, Y.; Ye, A. Single-cell discrimination based on optical tweezers raman spectroscopy. Chin. Sci. Bull. 2013, 58, 2594-2600. [CrossRef]

38. Zhang, Y.; Jin, L.; Xu, J.; Yu, Y.; Shen, L.; Gao, J.; Ye, A. Dynamic characterization of drug resistance and heterogeneity of the gastric cancer cell bgc823 using single-cell raman spectroscopy. Analyst 2018, 143, 164-174. [CrossRef] [PubMed]

39. Tu, L.; Zhang, L. Comparison of paclitaxel-induced apoptosis in human gastric cancer bgc-823 and sgc-7901 cell. Anhui Med. Pharm. J. 2010, 14, 141-142.

40. Wang, P.; Wang, C.; Wei, S.; Wang, C.; Hou, H. Establishment of cistplatin-resistant bgc 823/cddp cells. Chongqing Med. 2011, 40, 323-325.

41. Hammer, Ø.; Harper, D.A.T.; Ryan, P.D. Past: Paleontological statistics software package for education and data analysis. Palaeontol. Electron. 2001, 4, 10.

42. Kroemer, G.; Galluzzi, L.; Vandenabeele, P.; Abrams, J.; Alnemri, E.S.; Baehrecke, E.H.; Blagosklonny, M.V.; El-Deiry, W.S.; Golstein, P.; Green, D.R.; et al. Classification of cell death: Recommendations of the nomenclature committee on cell death 2009. Cell Death Differ. 2009, 16, 3-11. [CrossRef] [PubMed]

43. Danial, N.N.; Korsmeyer, S.J. Cell death: Critical control points. Cell 2004, 116, 205. [CrossRef]

44. Kroemer, G.; Galluzzi, L.; Brenner, C. Mitochondrial membrane permeabilization in cell death. Physiol. Rev. 2007, 87, 99-163. [CrossRef] [PubMed]

45. Owen, C.A.; Selvakumaran, J.; Notingher, I.; Jell, G.; Hench, L.L.; Stevens, M.M. In vitro toxicology evaluation of pharmaceuticals using raman micro-spectroscopy. J. Cell. Biochem. 2006, 99, 178-186. [CrossRef] [PubMed]

46. Notingher, I.; Selvakumaran, J.; Hench, L.L. New detection system for toxic agents based on continuous spectroscopic monitoring of living cells. Biosens. Bioelectron. 2004, 20, 780-789. [CrossRef] [PubMed]

47. De Gelder, J.; De Gussem, K.; Vandenabeele, P.; Moens, L. Reference database of raman spectra of biological molecules. J. Raman Spectrosc. 2007, 38, 1133-1147. [CrossRef] 
48. Zhu, Y.; Zhang, X.; Liu, Y.; Zhang, S.; Liu, J.; Ma, Y.; Zhang, J. Antitumor effect of the mtor inhibitor everolimus in combination with trastuzumab on human breast cancer stem cells in vitro and in vivo. Tumor Biol. 2012, 33, 1349. [CrossRef] [PubMed]

49. Jerusalem, G.; Fasolo, A.; Dieras, V.; Cardoso, F.; Bergh, J.; Vittori, L.; Zhang, Y.; Massacesi, C.; Sahmoud, T.; Gianni, L. Phase i trial of oral mtor inhibitor everolimus in combination with trastuzumab and vinorelbine in pre-treated patients with her2-overexpressing metastatic breast cancer. Breast Cancer Res. Treat. 2011, 125, 447-455. [CrossRef] [PubMed]

Sample Availability: Samples of the compounds are available from the authors.

(C) 2018 by the authors. Licensee MDPI, Basel, Switzerland. This article is an open access article distributed under the terms and conditions of the Creative Commons Attribution (CC BY) license (http:// creativecommons.org/licenses/by/4.0/). 